LA-UR- $98-2872$

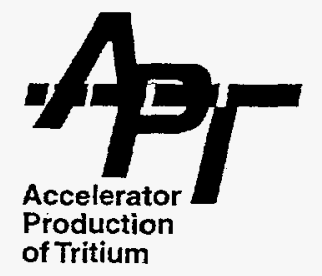

\title{
TECHNOLOGY BENEFITS RESULTING FROM ACCELERATOR PRODUCTION OF TRITIUM
}

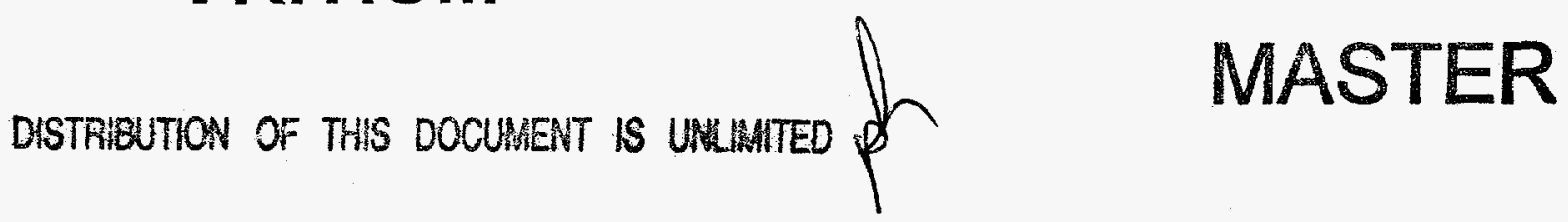

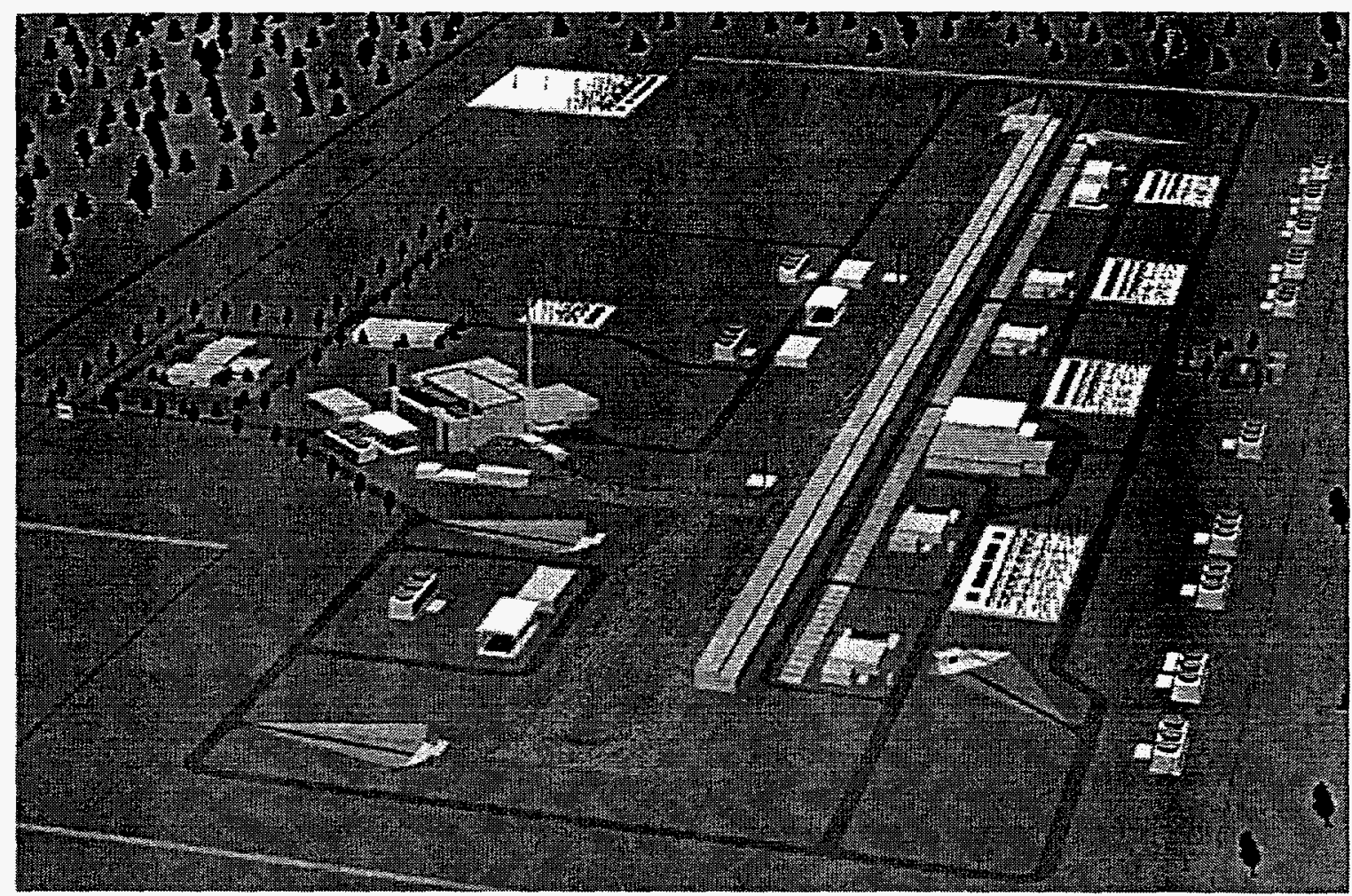


This repor was prepared as an account of work sponsored by an agency of the United States Government. Neither the United States Government nor any agency thereof, nor any of their employees, makes any warranty, express or implied, or assumes any legal liability or responsibility for the accuracy, completenees, or usefulness of any information, apparatus, product, or process disclosed, or represents that its use would not infringe privately owned rights. Reference berein to any specific commercial product, process, or service by trade name, trademark, imanufacturer, or otherwise does not necessarily constitute or imply its endorsement, recommendation, or favoring by the United States Government or any agency thereof. The views and opinions of authors expressed herein do not necessarily state or reflect those of the United States Governmeat or any agency thereof. 


\section{DISCLAIMER}

Portions of this document may be illegible in electronic image products. Images are produced from the best available original document. 


\section{TECHNOLOGY BENEFITS RESULTING FROM ACCELERATOR PRODUCTION OF TRITIUM}

\section{INTRODUCTION}

Centuries ago, alchemists dreamed of transforming lead into gold. The twentieth century has brought understanding of such nuclear transformations, also known as "transmutations," along with tools that make them possible- particle accelerators and nuclear reactors. It has also brought the ability to perform transformations much more valuable to mankind than gold, including the production of life-saving medical isotopes. Yet, we have barely begun to exploit the potential of such nuclear transformations, and our production technology is still maturing.

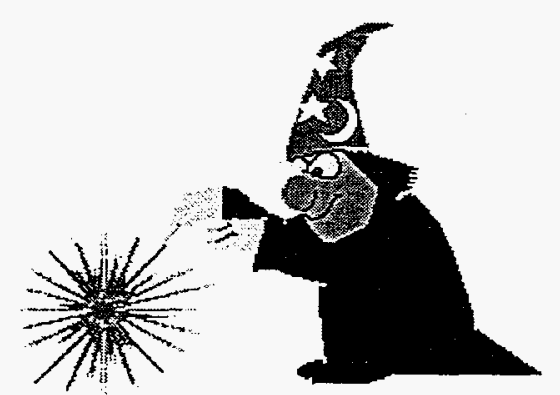

One of the early and most dramatic uses of nuclear transformations was in development of the nuclear weapons that brought World War II to an end. Despite that difficult introduction, nuclear weapons technology has been used largely as a deterrent to war throughout the latter half of the twentieth century. The Accelerator Production of Tritium (APT) offers a clean, safe, and reliable means of producing the tritium (a heavy form of hydrogen) needed to maintain our nuclear deterrent. Tritium decays away naturally at a rate of about $5.5 \%$ per year; therefore, the tritium reservoirs in nuclear weapons must be periodically replenished. In recent years this has been accomplished by recycling tritium from weapons being retired from the stockpile. Although this strategy has served well since the last U.S. tritium production reactor was shut down in 1988, a new tritium production capability will be required within ten years. Some benefits will result from direct utilization of some of the APT proton beam; others could result from advances in the technologies of particle accelerators and high power spallation targets.

\section{PRODUCING NEUTRONS AND TRITIUM USING ACCELERATORS}

Particle accelerators use electromagnetic fields to accelerate charged particles, such as protons, to high energies. Once the proton has sufficient energy, it can penetrate the nucleus of an atom and interact with the resident protons and neutrons. In some cases, the proton may slam directly into a neutron and dislodge it from the nucleus. More frequently, it simply deposits energy in the nucleus, leaving it in an excited state, resulting in a subsequent relaxation step called "evaporation." This results in some neutrons being emitted from the excited nucleus. By the time a high-energy proton 
interacts with a few atoms, giving off all its energy, dozens of neutrons may have been emitted. This process is called spallation, and the transformed atoms are called spallation products. Any material could be chosen as a target for the protons, but heavier materials, such as tungsten and lead, tend to provide more neutrons per unit of proton energy.

The nuclear transformation used in APT to make tritium is via capture of those neutrons in a helium isotope designated helium-3, since it has two protons and one neutron in the nucleus. When helium-3 captures a neutron, it quickly emits a proton and becomes tritium, having one proton and two neutrons. This simple transformation changes both the chemical and nuclear characteristics of the material.

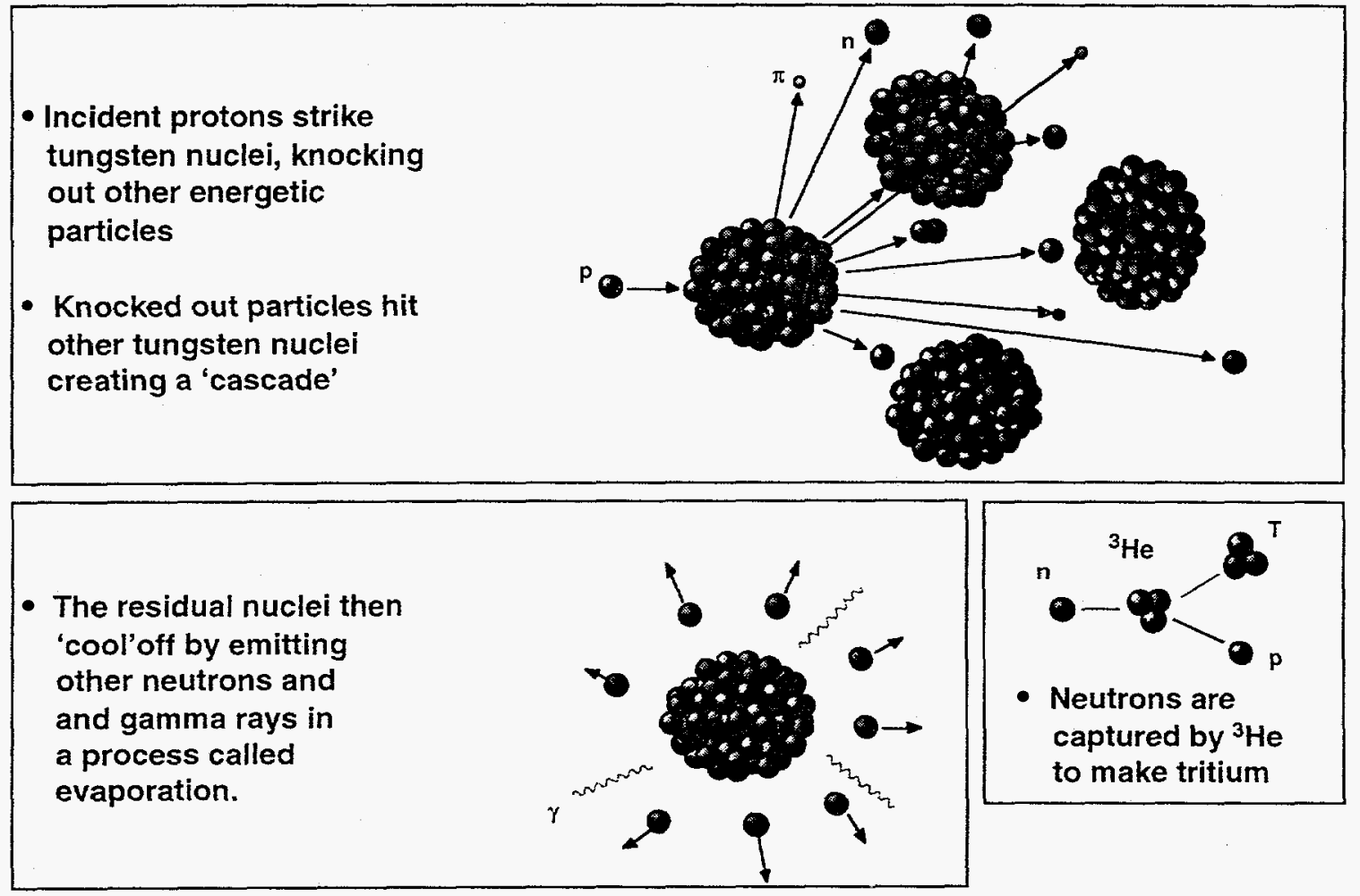

In APT, spallation and evaporation produce the neutrons used to make tritium.

\section{PRODUCING NEUTRONS AND ISOTOPES USING REACTORS}

There is an alternate option for making neutrons in large quantities, called fission, which involves splitting heavy atoms of materials such as uranium. This has the advantage of releasing a great deal of energy, in addition to neutrons and a couple of atoms that are roughly half as heavy as the fissioned atom. Thus, fission is effectively an exothermic (produces heat) process, while spallation is endothermic (requires energy/heat). The heat released by fission is utilized in nuclear power plants to produce electricity, but removal of the heat limits the number of neutrons that can be produced. 
For decades, some nuclear transformations were performed in nuclear reactors. Fission neutrons have been used to produce neutron-rich medical isotopes, tritium, and plutonium-238 for use as a power source in deep-space exploration. In some cases, fission products were harvested, including molybdenum-99, which decays to the technetium- $99 \mathrm{~m}$ used in millions of medical imaging procedures.

\section{PRODUCING ISOTOPES VIA SPALLATION}

Of the dozens of medical isotopes in use or testing, several are produced using reactors-via either neutron capture or the harvesting of fission products. Many other isotopes are produced using accelerators, most commonly via direct capture of protons. In addition, if an accelerator produces protons of sufficient energy, isotopes can be produced via spallation, then harvested.

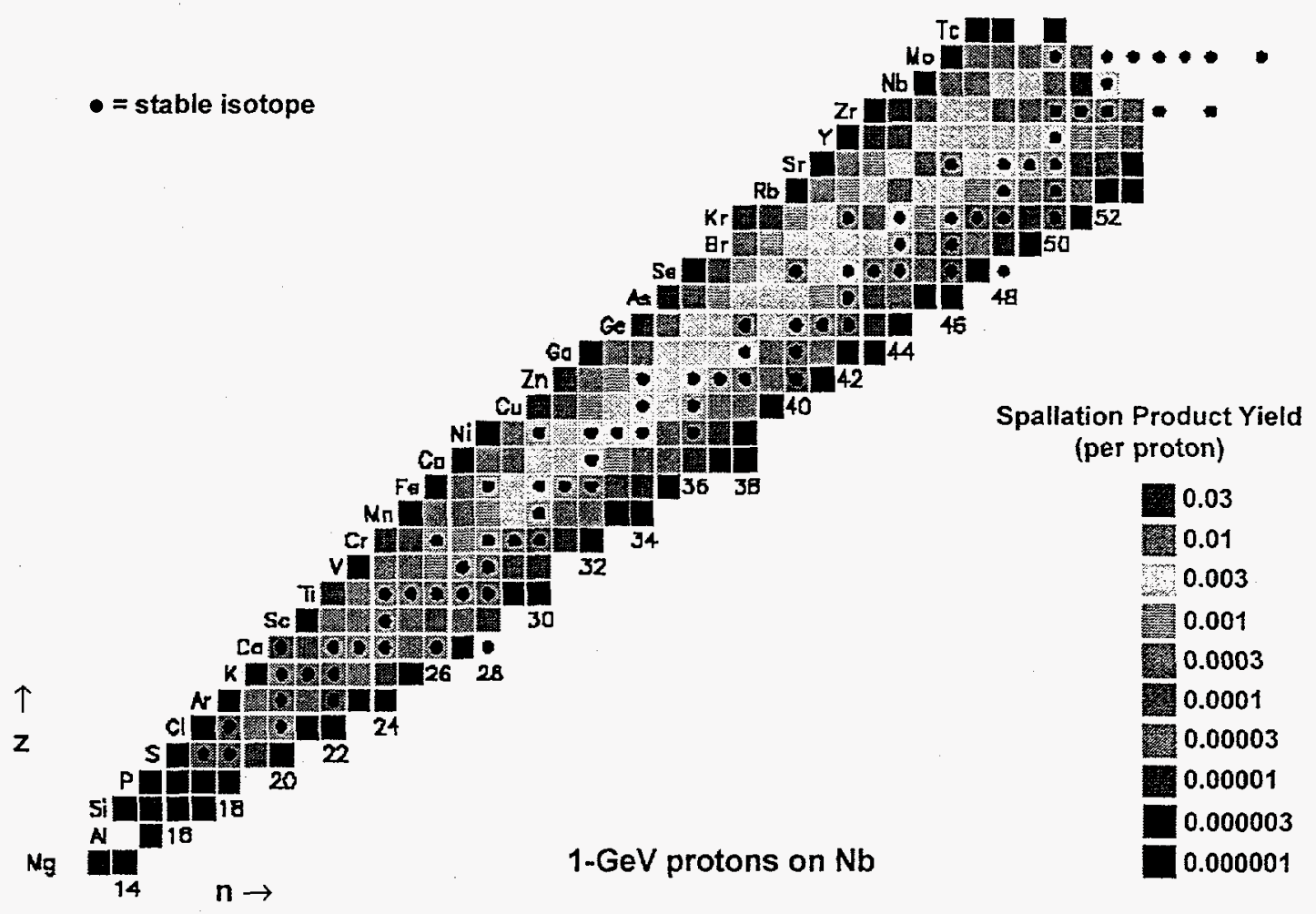

Hundreds of isotopes are produced by $1000 \mathrm{MeV}$ protons bombarding natural niobium. 


\section{PRODUCING ISOTOPES USING APT}

APT represents a hybrid option, as it has characteristics of both accelerators (protons to be captured or trigger spallation) and reactors (neutrons from spallation). Further, if one inserts small targets of thorium or uranium, a small amount of fission could be induced to

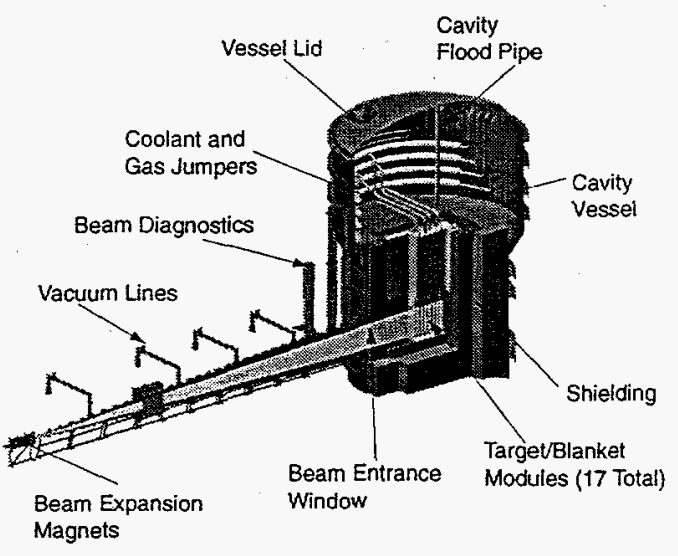

The APT target/blanket. produce and harvest fission products. This creates one machine with the potential of producing most isotopes, with a "full" range of options for producing nuclear transformations. The APT is primarily an isotope producer, as tritium is a heavy isotope of hydrogen. It will produce, as a byproduct, other useful isotopes via spallation and neutron capture, such as the cobalt-60 used widely for sterilization of medical instruments. Production of other isotopes is possible by adding other target materials to the APT.

The medical isotope market is currently dominated by a handful of tested and approved isotopes and medical procedures. However, there are many new procedures undergoing pre-clinical studies and clinical trials, and many of these rely on the so-called "designer isotopes." Some of these will be highly successful and save many lives. The APT capability for producing such isotopes is unprecedented, with its full range of capabilities for nuclear transformations. Further, because the quantity required is modest, APT production of most such isotopes would have an almost imperceptible impact on tritium production.

New medical isotopes can be transported to specific organs, such as the heart, to provide images of organ functions or deliver radiation doses specifically to the tumor site.

In contrast, production of Plutonium-238 would require several percent of the APT tritium production capability. It would also introduce more hazardous materials, such as neptunium and

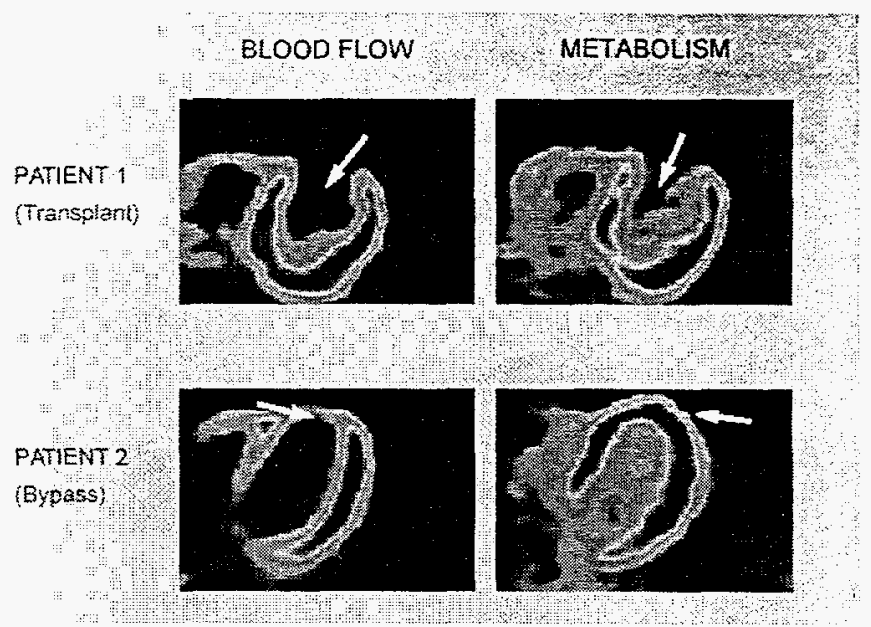
plutonium, into the APT target. Therefore, this is an instance where it may be better to build a separate accelerator-driven facility to perform the mission. 


\section{TRANSFORMING NUCLEAR WASTE}

While many radioisotopes are invaluable, some pose special problems. For example, the spent reactor fuel from nuclear power plants contains isotopes hazardous for millions of years. Because it is nearly impossible to engineer containers that will last more than a few centuries, most nations with nuclear power programs are struggling to develop waste repositories that will provide isolation for the requisite "geologic" time frame. Fortunately, it is only 1 to $2 \%$ of the spent fuel that poses the hazard. Further, there is the potential for using nuclear transformations to convert nearly all of the long-term hazards to materials that are either stable and harmless, or something that will be so within a few years. This has the potential of removing the "geologic" from waste repository, since the need for long-term isolation will be greatly diminished.

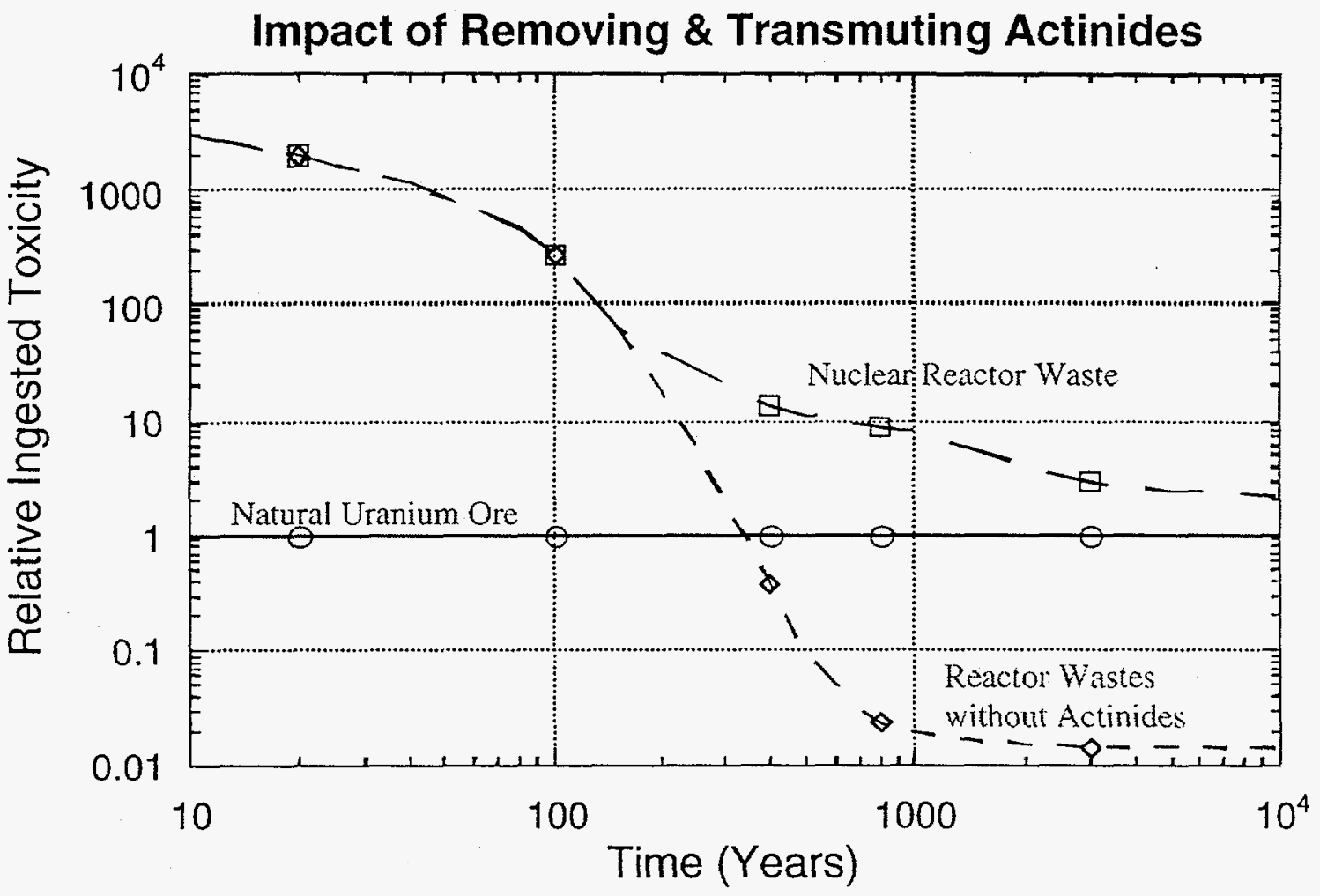

By transmuting long-lived isotopes, ATW can ease requirements for long-term isolation of nuclear wastes

Accelerator Transmutation of Waste (ATW) has the potential to fission the waste plutonium and higher actinides (similar to plutonium, but slightly heavier), and to convert long-lived fission products via neutron capture. The ATW can safely fission the plutonium and higher actinide feed stream without blending in uranium. (In contrast, the uranium content needed for stability in reactors would lead to the creation of additional plutonium and higher actinide wastes). In fissioning these wastes, ATW would produce electric power equivalent to about $17 \%$ of the current output of all the nuclear power plants in the U.S. A proton beam approximately $20 \%$ of APT beam could be used to 
drive a large ATW plant. If 10 to $20 \%$ of the APT beam capacity could be spared, ATW technology could be demonstrated at the APT site at Savannah River.

\section{ATW Consists of Three Major Functional Blocks}

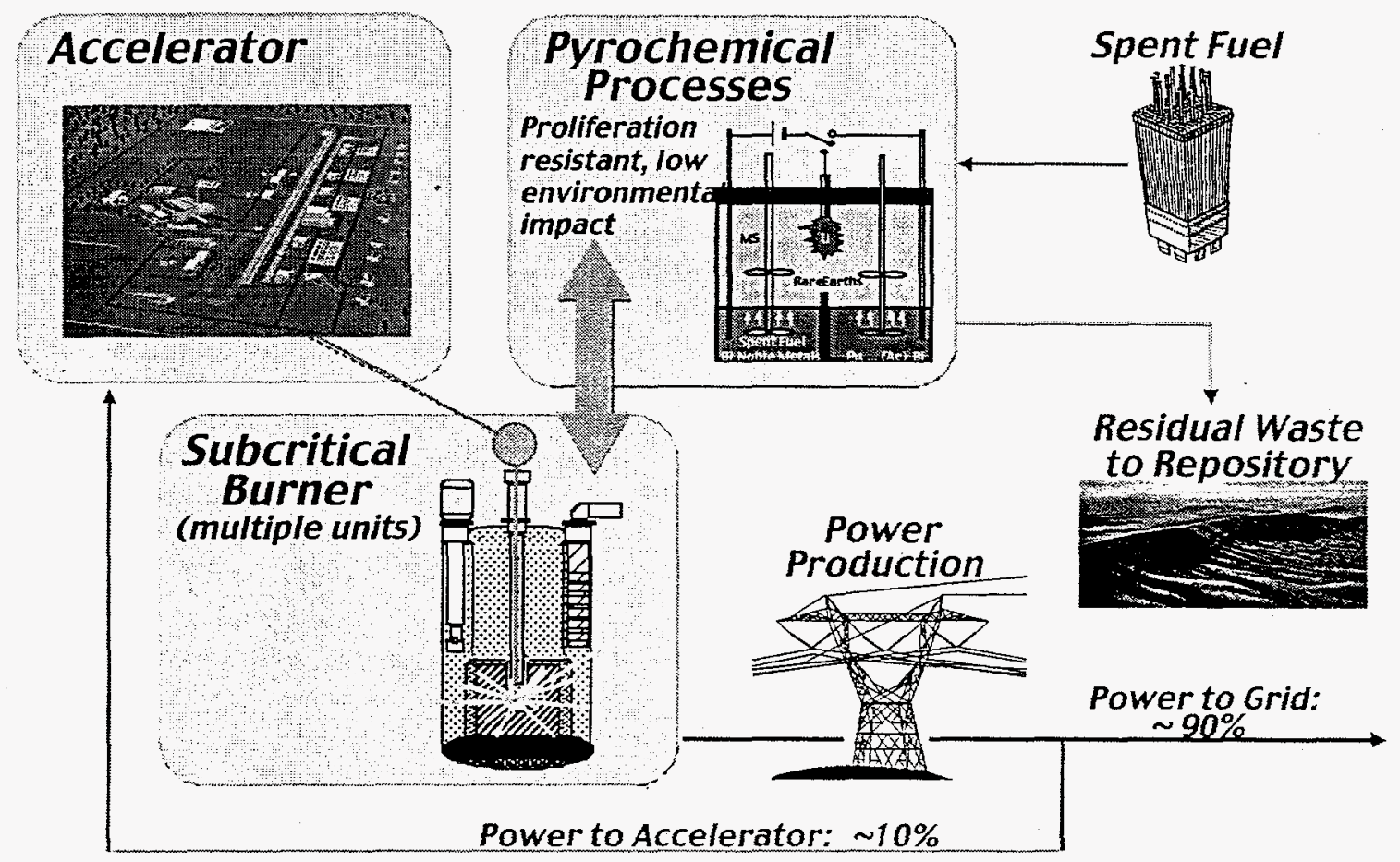

\section{THORIUM FUEL CYCLE}

The world derives its nuclear energy from a uranium-plutonium fuel cycle, which has the unfortunate consequence of producing a great deal of unused plutonium. When fissioned, plutonium produces useful energy. When left unused, plutonium poses a significant dual hazard. It is biologically hazardous. It is also a nuclear proliferation hazard, as most nuclear weapons are made using plutonium. ATW can help eliminate the plutonium inventory, but if it were possible to use a thorium-uranium fuel cycle, plutonium production would be effectively halted. 
Natural thorium is entirely stable thorium-232. When this isotope captures a neutron, it is transformed into uranium-233, which fissions efficiently. If one builds in enough uranium233 , the mix of thorium and uranium will sustain a nuclear reactor without producing significant quantities of plutonium. The biological hazards are much reduced, and any risk of nuclear weapons proliferation can be minimized through a process of blending with natural uranium, called "denaturing." A thoriumuranium cycle has been the Accelerator Initiates Thorium Cycle

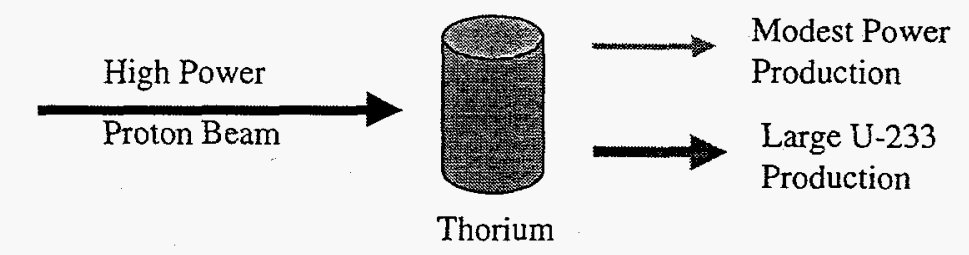

Accelerator Supports Power Production

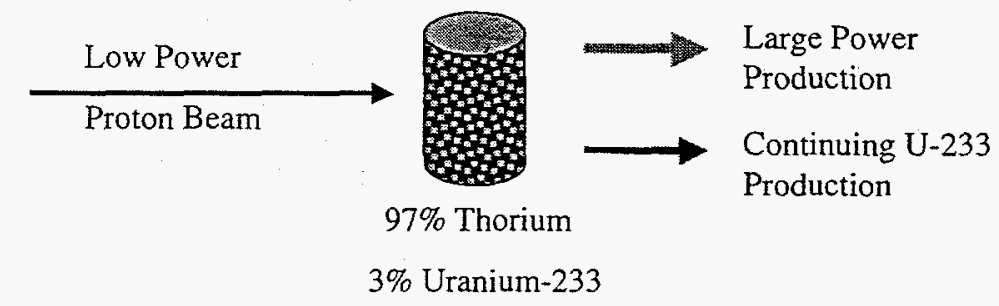

Accelerators can make a plutonium-free thorium cycle practical goal of some nuclear experts

for decades. Accelerator driven transformation of thorium can make it a reality.

\section{THE ACCELERATOR AS A PROBE}

Accelerator-driven particle beams have long been used to probe matter. There exist thousands of small accelerators that produce electrons or photons used for imaging patients, looking for tumors or the proper functioning of vital organs such as the heart. A new and unique imaging process, using high-energy protons, is currently under development to assure the safety and viability of aging nuclear weapons. This technology, called proton radiography, could be an important part of the Science-Based Stockpile Stewardship program tasked with safely maintaining the stockpile in the absence of periodic underground testing.

Neutrons are excellent material probes, and accelerators have been used to drive spallation neutron sources for decades. The pulsed nature of many accelerators allows researchers to use event-timing techniques that are impossible with continuous streams of neutrons. Thus, historically, the accelerators have been used for delivering pulsed streams of neutrons, and reactors have been used when large quantities of neutrons are desired on a continuous basis. However, problems in building new research reactors, in addition to a spallation target's advantage of much lower heat generation per neutron, suggest that accelerators may soon produce a larger share of the neutrons used by researchers. 


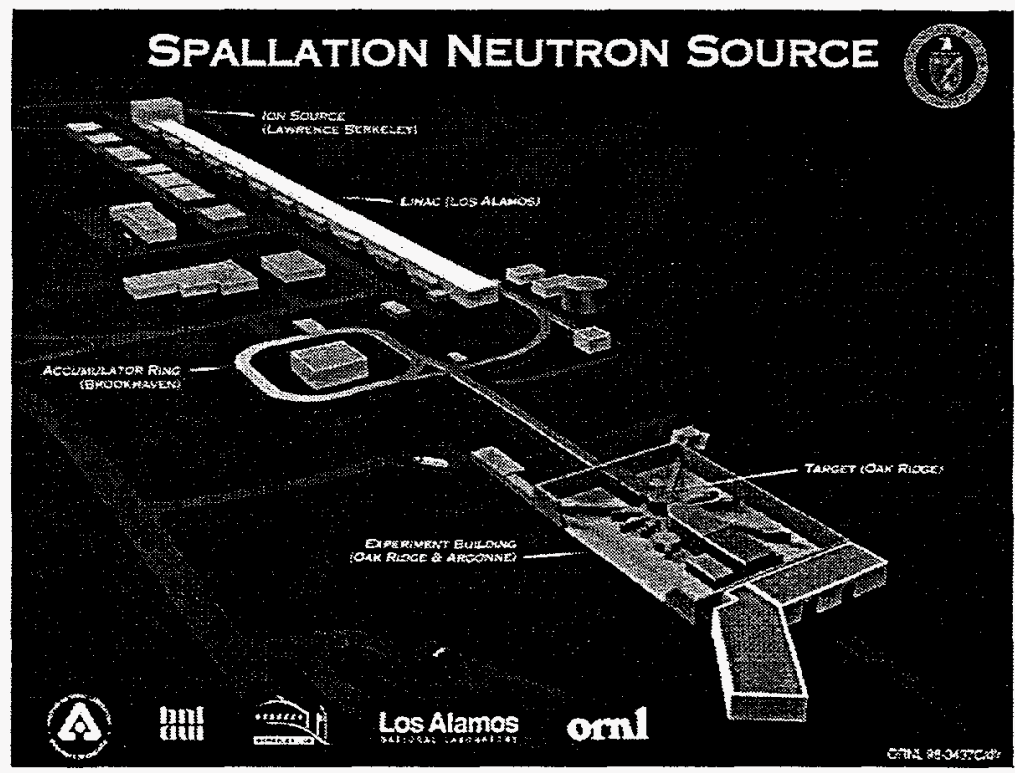

A new spallation neutron source is under development at Oak Ridge, Tennessee.

\section{EXAMINING THE BY-PRODUCTS}

While we use accelerators to perform nuclear transformations, other concurrent transformations are taking place that can help answer some of the fundamental questions of forefront science. For example, as APT makes tritium, it will be a source of neutrinos several hundred times more intense than any comparable source on earth. Because neutrinos interact so weakly with matter, we know very little about them, but they are one of the keys to understanding the origin and ultimately the future of the universe. The neutrinos generated by the APT will give researchers a unique opportunity to study neutrino properties, and thus, learn much more about an important and somewhat mysterious part of our universe.

On the other end of the scale, our understanding of how materials change when they are irradiated is largely determined through experience. For decades, scientists in the fusion community have wanted a source of neutrons like that found in the APT target to simulate a fusion reactor environment. APT will provide such an opportunity.

\section{THE PATH FORWARD}

The potential of accelerator technology to fulfill missions that have long been little more than dreams, is enormous. The path forward requires development of the large highpower linear accelerators, of which APT may be the first of several. The APT may save thousands of lives through the production of medical isotopes, and it may contribute to solving the nation's problem in disposing of long-lived nuclear wastes. But the most significant benefit may come from advancing the technology, so that the great potential of accelerator applications can be realized during our lifetimes. 


\section{CONTACTS}

Paul Lisowski

Los Alamos National Laboratory

Phone: 505-665-5523

James Anderson

Los Alamos National Laboratory

Phone: 505-665-4595

Carmelo Rodriguez

Burns \& Roe Enterprises, Inc. in association with General Atomics

Phone: 505-661-4410

Jimmy Angelos

Savannah River Site

Phone: 803-725-8593 